\title{
Coronary artery bypass grafting in a patient with gout arthritis
}

\author{
Murat Ugurlucan, Ugur Filizcan', Ilker Murat Caglar, Ertugrul Zencirci, Erhan Kaya ${ }^{2}$, \\ Mehmet Ugur Es ${ }^{1}$, Tayfun Gurol ${ }^{1}$, Yahya Yildiz ${ }^{2}$ \\ Duzce Ataturk State Hospital, Cardiovascular Surgery Clinic, Duzce, ${ }^{1}$ Maltepe University Medical Faculty, \\ Department of Cardiovascular Surgery, Istanbul, ${ }^{2}$ Pendik Bolge Hospital, Department of Cardiovascular \\ Surgery, Istanbul, Turkey \\ Address for correspondence: Dr. Murat Ugurlucan, Bozkurt Caddesi, No: 110-112, Benli Apt., Daire: 6, \\ 80250 Kurtulus / Istanbul, Turkey.E-mail: muratugurlucan@yahoo.com
}

\begin{abstract}
Ischemic heart disease is accepted as the most common cause of mortality and morbidity nearly all over the world. Gout disease is the most common condition of inflammatory arthritis among the adult population. Literature includes limited information about the treatment strategies when both the conditions coexist. In this report, we present the case report of a 63 year old male patient with the diagnosis of Gout arthritis who underwent a coronary artery bypass grafting procedure successfully.
\end{abstract}

Key words: Coronary artery bypass grafting, gout arthritis, hyperuricemia, ischemic heart disease

\section{INTRODUCTION}

Cardiovascular disorders are one of the the leading causes of mortality and morbidity today all over the world. They are endemic, and have been seen to increasingly affect a considerable number of people. They are also responsible for a major financial burden on the community and cause healthcare expenses. Although ischemic heart disease can be seen in different age groups, usually it is a disease of the aging population in whom related or un-related systemic disorders may also co-exist. On the other hand, other than the well known risk factors such as genetic inheritance, hyperlipidemia, cigarette smoking etc, it is well known that some of these co-existing systemic medical problems may also presdispose to coronary artery disease..$^{[1]}$

Gout disease is a metabolic arthritis. It is characterized with deposition of crystals of monosodium urate due to

\begin{tabular}{|l|l|}
\hline \multicolumn{2}{|c|}{ Access this article online } \\
\hline Quick Response Code: & Website: \\
\hline & www.jcdronline.com \\
\cline { 2 - 2 } & \\
\hline
\end{tabular}

the increased circulating levels of uric acid in the blood. ${ }^{[2]}$ Literature includes scant reports about the co-existance of Gout arthritis and ischemic heart disease, or hyperuricemia related coronary artery disease. ${ }^{[1,3-13]}$ In this report, we present pre-, peri-, and post-operative strategies in a 63-year-old male patient with the history of Gout disease, and who underwent a successful surgical treatment for coronary artery disease.

\section{CASE REPORT}

The patient was a 63-year-old white Turkish male living in Istanbul, Turkey who presented to the clinic with increasing chest pain on exertion, which had progressed in the last six months. He was $169 \mathrm{~cm}$ tall and weighed $74 \mathrm{~kg}$. He had been a smoker for more than 45 years, and on an average smoked 1-1.5 packs per day. His family history was negative for cardiovascular disorders. He was not hypertensive (blood pressure of $128 / 76 \mathrm{mmHg}$ on left arm and 132/77 mmHg on right arm at rest) and did not have diabetes mellitus (overnight fasting blood glucose of $98 \mathrm{mg} / \mathrm{dL}$, normal range: $<100 \mathrm{mg} / \mathrm{dL})$. Blood lipid profile indicated total cholesterol and low density lipoprotein levels of $193 \mathrm{mg} /$ $\mathrm{dL}$ (normal range: $<200 \mathrm{mg} / \mathrm{dL}$ ) and $124 \mathrm{mg} / \mathrm{dL}$ (normal range: $<130 \mathrm{mg} / \mathrm{dL}$ ), respectively. Cardiologic check up protocol was considered and the patient underwent stress 
electrocardiography which resulted positive. Myocardial thallium perfusion scintigraphy indicated ischemic zones at the inferior, inferolateral and inferoapical zones of the heart. According to the results, coronary angiography was performed and it revealed triple vessel disease with subtotal occlusion of left anterior descending artery (LAD) at the midportion, midportion $80 \%$ stenosis at the circumflex coronary artery $(\mathrm{Cx})$ and $70 \%$ stenosis at the right coronary artery (RCA). Echocardiography was normal with preserved left ventricular functions $(65 \%$ ejection fraction) and left ventricular hypertrophy. Following the consent of the patient, coronary artery bypass grafting (CABG) was planned.

During the preparatory phase for surgery, the patient complained of acute first toe pain. The first toe looked swollen, hyperemic and painful on palpation. Laboratory findings including complete blood count, blood lipid profile, renal and hepatic enzymes, clotting times, were normal except increased serum uric acid levels $(10.74 \mathrm{mg} /$ $\mathrm{dl}$, Normal: $3.4-7 \mathrm{mg} / \mathrm{dl}$ ) and slighly elevated C-reactive protein $(6.72 \mathrm{mg} / \mathrm{L}$, Normal: $0-5 \mathrm{mg} / \mathrm{L})$. He was consulted with internal medicine department and diagnosed as Gout arthritis. He was prescribed allopurinol $300 \mathrm{mg}$ twice daily and scheduled for surgery when the circulating uric acid levels returned to normal. Following four days of treatment, uric acid levels returned to normal limits, and he underwent triple vessel CABG (Left internal mammarian artery to LAD, aorta-first obtuse marginal artery and aortaposterior descending branch of the right coronary artery bypasses with separate saphenous veins) with the use of cardiopulmonary bypass on arrested heart at $33-34^{\circ} \mathrm{C}$. Cross clamp and cardiopulmonary bypasses were 35 minutes and 47 minutes, respectively. After the operation, the patient was transferred to the intensive care unit and extubated there on the post-operative $4^{\text {th }}$ hour. He was taken to the ward the next day and discharged on the 6th day. Blood and blood product usage was 1 units of erythrocyte suspension and 2 units of fresh frozen plasma in total.

Immediately after the surgery, there was a slight increase in serum uric acid levels $(7.4 \mathrm{mg} / \mathrm{dl})$ detected in the blood drawn in the intensive care unit. As soon as the patient was extubated and oral intake was started, allopurinol was initiated at the same pre-operative dosage, and this returned the serum uric acid levels to normal. Post-operative course was otherwise uneventful. He has been followed symptom free for more than 9 months and is on allopurinol treatment in addition to anti-aggregant (aspirin, 100mg daily), antilipidemic (atorvastatin, 20mg daily) and low dose betablocker (metoprolol $25 \mathrm{mg}$ daily) medications and a low calori diet.

\section{DISCUSSION}

Coronary artery disease is the leading cause of mortality and morbidity worldwide in the current decade. With the advances in medical knowledge about the different pathophysiologic events leading to ischemic heart disease, diagnostic methods and treatment strategies, various therapeutic measures are now-a-day performed to prevent, diagnose, treat and obtain deeper knowledge about the disease. It is very well known that there are certain risk factors such as genetic susceptibility, hypertension, hyperlipidemia, smoking, and diabetes mellitus, which may predispose an individual to coronary artery disease. Additionally, hyperhomocysteinemia and metabolic syndromes have been identified as other risk factors for the disease as well as predictors of the success of the treatment and survival of the patients. ${ }^{[1]}$ Recently, elevated serum uric acid level is identified as an independent risk factor for cardiovascular diseases..$^{[1,3-13]}$ Several prospective studies have shown an association between hyperuricemia and cardiovascular diseases and death. ${ }^{[1,5-7,10,11]}$ In our case, the patient only had smoking as a major cardiovarcular risk factor, and otherwise he was not hypertensive, hyperlipidemic, or diabetic, and did not define positive family history. We may speculate that in addition to the over 45 years of cigarettes smoking history, increased serum uric acid levels might have increased the risk of coronary artery disease or have exacerbated the symptoms of the patient in our case study.

Gout is a kind of acute inflammatory arthritis, and characterized by recurrent painful attacks. In more than half of the patients, the metatarsophalangeal joint is the most commonly affected region as well as the presenting symptom of the patients in the clinic. The pathology is caused by the crystalization, accumulation and deposition of elevated levels of uric acid of monosorium urate character in the blood, at the joints, tendons, cartilages, and the surrounding tissues. This leads to painful attacks. Additionally, the disease may also present as tophi, kidney stones, or urate nephropathy. ${ }^{[2]}$ It has been shown that chronic inflammatory disorders such as systemic lupus erythematosus, rheumatiod arthritis, ankylosing spondilitis, diabetes mellitus, etc are associated with shorter life expectancy in affected individuals as compared to the general population. ${ }^{[1]}$ On the other hand, hyperuricemia is associated with reduced survival due to increased tendency to obesity, hypertension, insulin resistance, diuretic usage and renal disease. ${ }^{[1]}$ The National Health and Nutrition Examination Survey I Follow-Up Study reported that serum uric acid was an independent predictor of cardiovascular 
mortality in subjects above 45 years of age regardless of race, menopausal status, diuretic use, or presence of cardiovascular disease. ${ }^{[6]}$ The Framingham Study showed that serum urate levels were not independently associated with the risk of coronary heart disease; however, Gout was associated with a $60 \%$ increased risk of coronary artery disease. ${ }^{[5]}$ A recent study, based on the Multiple Risk Factor Intervention Trial reports that Gout may lead to upto $26 \%$ increased risk of acute myocardial infarction. ${ }^{[3]}$ Choi et al., ${ }^{[14]}$ in their 12 years Health Professionals Follow-Up Study, which included 51,297 male participants, strongly support the link between hyperuricemia, Gout, and cardiovascular diseases.

Although a clear mechanism indicating the consequences of hyperuricemia on cardiovascular diseases and decreased survival could not be identified, a recent novel rodent model showed that that uric acid could cause renal afferent arteriolopathy and tubulointerstitial disease, which leads to hypertension. ${ }^{[15]}$ When the serum uric acid levels are reversed, the renal lesions and hypertension were prevented..$^{[9,11,14]}$ Another explanation for the increased cardiovascular disease rate in the presence of Gout may be the ongoing and relapsing inflammation due to hyperuricemia among patients with the disease, which might enhance and promote atherogenesis and thrombogenesis, as seen in other inflammatory rheumatic disorders. ${ }^{[11,12]}$

In conclusion, patients with Gout have higher risks of cardiovascular disorders, myocardial infarction and death due to increased blood uric acid levels. As sson as hyperuricemia has been diagnosed, strict control of Gout should be aimed for, to prevent any systemic complications ${ }^{[12,13]}$ as well as cardiovascular consequences. This can be achieved with a multidisciplinary approach through the usage of well known cardioprotective medications such as aspirin, statins, beta-blockers when needed, and angiotensin converting enzyme inhibitors following coronary artery bypass grafting.

\section{REFERENCES}

1. Choi HK, Curhan G. Independent impact of gout on mortality and risk for coronary heart disease. Circulation 2007;116:894-900.

2. Choi HK, Mount DB, Reginato AM. Pathogenesis of gout. Ann Intern Med 2005;143:499-516.

3. Krishnan E, Baker JF, Furst DE, Schumacher HR. Gout and the risk of acute myocardial infarction. Arthritis Rheum 2006;54:2688-96.

4. Tavil Y, Sen N, Hizal F, Açikgöz SK, Taşoğlu I, Topal S, et al. Relationship between elevated levels of serum uric acid and saphenous vein graft disease. Turk Kardiyol Dern Ars 2008;36:14-8.

5. Culleton BF, Larson MG, Kannel WB, Levy D. Serum uric acid and risk for cardiovascular disease and death: The Framingham Heart Study. Ann Intern Med 1999;131:7-13.

6. Fang J, Alderman MH. Serum uric acid and cardiovascular mortality the NHANES I epidemiologic follow-up study, 1971-1992. National Health and Nutrition Examination Survey. JAMA 2000;283:2404-10.

7. Nagahama K, Iseki K, Inoue T, Touma T, Ikemiya Y, Takishita S. Hyperuricemia and cardiovascular risk factor clustering in a screened cohort in Okinawa, Japan. Hypertens Res 2004;27:227-33.

8. Leyva F, Anker S, Swan JW, Godsland IF, Wingrove CS, Chua TP, et al. Serum uric acid as an index of impaired oxidative metabolism in chronic heart failure. Eur Heart J 1997;18:858-65.

9. Johnson RJ, Kang DH, Feig D, Kivlighn S, Kanellis J, Watanabe S, et al. Is there a pathogenetic role for uric acid in hypertension and cardiovascular and renal disease? Hypertension 2003;41:1183-90.

10. Niskanen LK, Laaksonen DE, Nyyssonen K, Alfthan G, Lakka HM, Lakka TA, et al. Uric acid level as a risk factor for cardiovascular and all-cause mortality in middle-aged men: A prospective cohort study. Arch Intern Med 2004;164:1546-51.

11. Franse LV, Pahor M, Di Bari M, Shorr RI, Wan JY, Somes GW, et al. Serum uric acid, diuretic treatment and risk of cardiovascular events in the Systolic Hypertension in the Elderly Program (SHEP). J Hypertens 2000;18:1149-54.

12. Doehner W, Schoene N, Rauchhaus M, Leyva-Leon F, Pavitt DV, Reaveley DA, et al. Effects of xanthine oxidase inhibition with allopurinol on endothelial function and peripheral blood flow in hyperuricemic patients with chronic heart failure: Results from 2 placebo-controlled studies. Circulation 2002;105:2619-24.

13. Farquharson CA, Butler R, Hill A, Belch JJ, Struthers AD. Allopurinol improves endothelial dysfunction in chronic heart failure. Circulation 2002;106:221-6.

14. Choi HK, Atkinson K, Karlson EW, Curhan G. Obesity, weight change, hypertension, diuretic use, and risk of gout in men: The Health Professionals Follow-Up Study. Arch Intern Med 2005;165:742-8.

15. Mazzali M, Hughes J, Kim YG, Jefferson JA, Kang DH, Gordon KL, et al. Elevated uric acid increases blood pressure in the rat by a novel crystalindependent mechanism. Hypertension 2001;38:1101-6.

How to cite this article: Ugurlucan M, Filizcan U, Caglar IM, Zencirci E, Kaya E, et al., Gurol T, Yildiz Y. Coronary artery bypass grafting in a patient with gout arthritis. J Cardiovasc Dis Res 2012;3:52-4. Source of Support: Nil, Conflict of Interest: None declared. 